\title{
ENTRE NARRATIVAS LITERÁRIAS E HISTORIOGRÁFICAS, AS MULHERES NO MOVIMENTO DO CONTESTADO: "VIRGENS" OU PROTAGONISTAS?
}

\author{
Claudia Priori* \\ Fábio da Silva Smoliak**
}

\begin{abstract}
Resumo: Este artigo tem como objetivo analisar, numa perspectiva interdisciplinar, a construção de narrativas literárias acerca da participação feminina no movimento do Contestado que se desenrolou no Brasil, no início do século XX, relacionando-as com as narrativas historiográficas. Para isso, apresentamos o contexto histórico e a relação entre literatura e historiografia, discutindo como se constroem as representações das mulheres envolvidas no movimento e como são retratadas nas obras utilizadas como fontes: Império caboclo, de 2005, escrita por Donaldo Schüler, e O bruxo do Contestado, de 1996, escrita por Godofredo de Oliveira Neto. Temos com referenciais a história das mulheres e os estudos de gênero que possibilitam abordar questões sociais e culturais e a construção narrativa das representações femininas e da visão dicotômica entre "virgens" ou protagonistas no movimento, que perpassam as fontes da pesquisa. Assim, a comparação entre as obras literárias analisadas e a relação entre a história e a literatura revelaram debates de época, similaridades e representações variadas, denotando a maneira como as mulheres do Contestado são retratadas, ora como "virgens", pacíficas, passivas, ora como guerreiras, ativas, protagonistas no processo histórico.
\end{abstract}

Palavras-chave: Mulheres. Contestado. Representação. Literatura. Narrativa.

\section{TECENDO AS PRIMEIRAS CONSIDERAÇÕES...}

0 protagonismo feminino na história dos movimentos sociais, na politica, na sociedade e na cultura brasileira tem sido tema de variadas pesquisas e publicações na historiografia contemporânea, e isso se deve, principalmente, à emergência do campo a partir dos anos 1960 e, nas últimas décadas, ao campo dos estudos de gênero que têm abordado a presença e participação das mulheres em vários âmbitos e contextos históricos, numa perspectiva das

\footnotetext{
*E-mail: claudiapriori@bol.com.br

**E-mail: fwosniak@gmail.com
} 
relações de gênero. Além disso, há que se mencionar o diálogo com outras áreas, como a antropologia, a sociologia, a literatura, as artes e a ciência política.

A produção historiográfica sobre a história das mulheres se acentuou a partir das décadas de 1970 e 1980 e trouxe para a visibilidade social novas temáticas, problematizações e abordagens acerca das experiências das mulheres tanto no âmbito privado quanto na esfera pública, o que reforçava a consolidação do campo da história das mulheres e a relação interdisciplinar com a sociologia e a antropologia, especialmente.

A emergência dos estudos de gênero e sua consolidação no Brasil tiveram como referencial a historiadora e teórica Joan Scott (1990), com a publicação de seu artigo "Gênero: uma categoria útil de análise histórica", o que influenciou consideravelmente as pesquisas no país que adotaram a categoria gênero como uma categoria analítica.

Nesse cenário, o campo da história das mulheres encontrava no diálogo interdisciplinar um espaço de proliferação para produções científicas, como ressaltam Rachel Soihet e Joana Maria Pedro (2007, p. 287):

0 desenvolvimento de novos campos tais como a história das mentalidades e a história cultural reforça o avanço na abordagem do feminino. Apóiam-se em outras disciplinas tais como a literatura, a lingüística, a psicanálise e, principalmente, a antropologia -, com o intuito de desvendar as diversas dimensões desse objeto. Assim, a interdisciplinaridade assume importância crescente nos estudos sobre as mulheres.

Partindo de uma perspectiva interdisciplinar, objetivamos neste trabalho analisar a construção de narrativas literárias acerca da participação feminina no movimento do Contestado que se desenrolou no Brasil, no início do século XX, relacionando-as com as narrativas historiográficas, buscando perceber os papéis atribuídos às mulheres e o grau de importância que, ao longo da construção narrativa, elas tiveram, ora sendo evidenciadas, ora sendo excluídas como agentes integrantes do movimento.

Em meio à ampla quantidade de obras literárias, selecionamos apenas duas para análise: Império caboclo, de 2005 escrita por Donaldo Schüler², e O bruxo do Contestado, de 1996,

\footnotetext{
1 - Utilizamos a expressão "movimento do Contestado" para nos referirmos a uma ação coletiva de um grupo organizado que tem como objetivo alcançar mudanças sociais e ainda pelo intuito de retirar um caráter "clássico" de escrita que se remete a uma história de grandes homens e grandes batalhas, e que omite muitos(as) personagens para dar visibilidade a personagens muitas vezes esquecidos(as) nas narrativas acerca do movimento. Entretanto, os autores das obras analisadas - fontes - utilizam a expressão "Guerra do Contestado", e por isso, em alguns pontos do texto, faremos uso também dessa expressão.

2 - Donaldo Schüler é natural de Videira, Santa Catarina. É doutor em Letras e livre-docente pela Universidade Federal do Rio Grande do Sul (UFRGS). Realizou pós-doutorado na Universidade de São Paulo (USP). Ministrou cursos em nível de graduação e de pós-graduação no Brasil e no exterior. Atua como conferencista e professor em várias instituições e universidades.
} 
escrita por Godofredo de Oliveira Neto ${ }^{3}$. Ambas são categorizadas como romances brasileiros que constroem narrativas que envolvem o entorno ou têm como cenário de fundo o movimento do Contestado. Essas obras são o resultado de anos de estudos de ambos os escritores, que absorveram aspectos históricos nas suas narrativas sobre o movimento. Por conhecerem os acontecimentos e as versões deles, utilizaram-nos para reeditar um passado e, dessa reconstrução, exibem ou tentam exibir agentes antes esquecidos(as), os quais podem expressar o ideal do presente em que as obras foram escritas.

A utilização da literatura como fonte histórica nos permite compreender e relacionar a construção de um fato histórico e, ao mesmo tempo, contribui para percebermos como se constroem e se reproduzem os papéis sociais e as relações de gênero nas obras literárias, e também como esses estereótipos se difundem para a sociedade criando ou excluindo personagens históricos e forjando narrativas.

\section{HISTÓRIA E LITERATURA COMO REPRESENTAÇÕES: POSSIVEEIS DIFERENCIAÇÕES NAS NARRATIVAS}

A literatura - no cenário de modificações de escrita da história trazido com o advento da Escola dos Annales - passa a ser vista e utilizada como fonte para a pesquisa historiográfica. É na mudança do foco de abordagem histórica que a literatura contribui de maneira significativa para a disciplina histórica, sem perder a cientificidade, como salienta Bethânia Cristina Gaffo (2003), o que justifica nossa escolha pela literatura, uma vez que há várias produções acerca do movimento do Contestado, narrativas de não historiadores(as) ${ }^{4}$. Um ponto importante a ser destacado nessa relação interdisciplinar seria verificar se as mudanças na escrita da história também se refletiram nas obras literárias e se conseguiram ultrapassar as fronteiras dos campos e mesclar-se à literatura e se foram utilizados fundamentos da história

3 - Godofredo de Oliveira Neto é doutor em Letras pela Universidade Federal do Rio de Janeiro (1989) e pós-doutor com pesquisa pela Georgetown University. É romancista e contista. É professor de Literatura Brasileira nos cursos de graduação e pós-graduação da Universidade Federal do Rio de Janeiro (UFRJ) desde 1980.

4 - Geração do deserto (1964), de Guido Wilmar Sassi; Eles não acreditavam na morte (1978), de Fredericindo Marés de Souza; Império caboclo (1994), de Donaldo Schüler; Casa verde - Guerra do Contestado (1981), de Noel Nascimento; 0 jagunço - Um episódio da Guerra do Contestado (1978), de Fernando Osvaldo de Oliveira (1978); O dragão vermelho do Contestado (1998) e Chica Pelega. Tragédia histórica (2000), ambos de A. Sanford de Vasconcellos; Glória até o fim - espionagem militar na Guerra do Contestado (1998), de Telmo Fortes; Os rebeldes brotam da terra (1995), de Alcides Ribeiro J. da Silva; O bruxo do Contestado (1996), de Godofredo de Oliveira Neto; Chica-Pelega do Taquaruçu (2000), de Cirila de Menezes Pradi. Obras interessantes também são: Pequena história dos fanáticos do Contestado (1955), de Brasil Gerson; 0 último jagunço (1995), de Euclides J. Felipe; Lendas caboclas do Contestado (1989); Demônios do Planalto (1995), de Aracyldo Marques; Odisséia no Contestado (1988), de Evaldo Trierweiler; e História do monge João Maria (1985), com lendas atribuidas ao monge, de Augusto Waldrigues. Destacamos ainda: $O$ canto do inhambu (1991), de Rudney Otto Pfützenreuter, e Barabas (2005), de Adolfo Boss Júnior. 
para criar o pano de fundo para uma abordagem literária e ao mesmo tempo não perder a sua historicidade.

0 movimento do Contestado ocorreu entre Paraná e Santa Catarina, entre os anos de 1912 e $1916^{5}$. Em uma disputa de terras em suas delimitações como estados da Federação, envolvia uma área de aproximadamente 15 mil km², como aponta Nilson Thomé (2016). 0 conflito deixou rastros de sangue, ceifando a vida de milhares, entre civis e militares. Cabe salientar que, no período em estudo, o Exército brasileiro não tinha uma participação feminina no conflito, pelo menos não de forma declarada, já que somente em 1943, durante a Segunda Guerra Mundial, as mulheres oficialmente ingressaram no Exército (EXÉRCITO BRASILEIRO, 2017).

A historiografia relata que o início da Guerra do Contestado ocorreu com a chamada Batalha de Irani, em 1912, entretanto, vale lembrar que as tensões sociais, políticas, econômicas e religiosas já estavam sendo polarizadas antes mesmo dessa batalha que matou dezenas de pessoas, entre elas os chefes dos grupos em confronto - o coronel João Gualberto Gomes de Sá e o próprio monge José Maria. A batalha foi o estopim para que, ao longo de quatro anos - de 1912 a 1916 -, a Guerra do Contestado deixasse cerca de dez mil mortos: "A população cabocla da região, que era profundamente mística e praticante de um catolicismo rústico, foi praticamente exterminada nesse periodo" (ANTONELLI, 2013, p. 1).

\footnotetext{
Um elemento que contribuiu fortemente para a instabilidade social na região contestada, bem como no conjunto do planalto Catarinense, foi a introdução da ferrovia. [...] A empresa concessionária responsável pela exploração da linha por 90 anos era a Brazil Railway, formada pelo magnata norte-americano Percival Farquhar, com a contribuição de capitais ingleses e franceses, a qual, além da garantia de juros em caso de prejuízo, recebia como doação por parte do governo federal um trecho de até 15 quilômetros de terras de cada margem da linha (TRENTO; LUDKA; FRAGA, 2014, p. 175).
}

Além disso, havia também outro elemento importante para o início do conflito: o messianismo. A região era frequentada por monges $^{6}$ que faziam trabalhos sociais e espirituais, e, vez ou outra, envolviam-se também com questões políticas - o que Ihes dava certo destaque entre as pessoas moradoras daquela localidade. Em 1912, apareceu na região um monge

5 - Há uma vasta historiografia produzida sobre o conflito, desde os trabalhos considerados "clássicos", como os de Maria I. P de Queiroz, Maurício Vinhas de Queiroz e Duglas Teixeira Monteiro, até os estudos mais recentes, como os de Paulo Derengoski, Marli Auras, Ivone Gallo, Paulo Pinheiro Machado, entre outros.

6 - A região do Contestado foi largamente percorrida por dois monges, de 1845 a 1908. 0 primeiro se chamava João Maria D'Agostini e era italiano de origem. Desapareceu por volta de 1890. Em seguida, surge outro monge, João Maria de Jesus, nome adotado por Anastás Marcaf, turco de origem. Desapareceu por volta de 1908. Um terceiro monge, entretanto, vai aglutinar o povo do sertão do Contestado: José Maria de Santo Agostinho, cujo verdadeiro nome era Miguel Lucena. Este sugeria ser irmão de João Maria. 
chamado José Maria de Santo Agostinho, nome que mais tarde a polícia descobriria ser falso. José Maria foi saudado por habitantes do local como sendo a ressurreição de outro monge que vivera ali até 1908, o monge João Maria: era como se o antigo líder espiritual tivesse voltado, afirma Nilson César Fraga (2006).

\begin{abstract}
Havia vários interesses em jogo: disputas pela exploração dos ervais, disputas eleitorais entre coronéis, a utopia de construir uma sociedade mais justa, sem falar no messianismo e fanatismo que tanto influenciaram a população cabocla. Todos esses fatores sustentaram um confronto sangrento entre o séquito de José Maria e as tropas governamentais que só chegou ao fim em agosto de 1916, com a prisão do último líder dos caboclos, chamado Adeodato (BARBOSA, 2011, p. 66).
\end{abstract}

Cabe problematizarmos que, pelo lado dos "rebeldes", os civis estavam a se erguer contra o Estado e que não podiam dar-se ao luxo de expulsar o efetivo feminino ou masculino. Por conta disso, relega-se, na maioria das vezes, ao esquecimento o papel que as mulheres ocuparam. 0 episódio do movimento do Contestado repleto de contradições, com nomenclaturas diferenciadas - "movimento", "campanha", "guerra" e "luta" -, já demonstra a desigualdade em questão do presente em que foi escrito, com distintos olhares, com dissonantes abordagens teórico-metodológicas e posicionamentos políticos. Assim, trabalhar com as fontes literárias tidas como ficção nos revela muito do presente em que foram escritas, problematizando a construção de narrativas acerca da participação das mulheres, quase um século após o episódio.

$\mathrm{Na}$ ficção, a presença de personagens femininas que fizeram toda a diferença na luta, contrapondo com o discurso da história oficial, que afirma ter, esta guerra, pertencido a homens; as mulheres, quando citadas, aparecem ou como divindades, no caso das Virgens, ou como figuras submissas, pacíficas e até mesmo como estorvos nos momentos em que estourava cada combate (SILVEIRA, 2008, p. 1-2).

Com vistas a olhar para além do messianismo ou de homens pegando em armas e se digladiando, buscamos entender o movimento pela ótica das relações de gênero, já que, pelo lado civil, o conflito acaba nivelando os gêneros em prol dos objetivos de se manterem vivos e protegerem suas famílias. Assim, rompendo com a ideia de conflito armado, em que os homens eram os atores e as mulheres continuavam sua vida de modo paralelo e à margem dos acontecimentos, quase divinas, colocadas num altar, ou pacíficas, submissas e, ainda, como estorvos, já que podiam significar um peso na hora dos confrontos, como assinala Claudia Regina Silveira (2008), ansiamos novas possibilidades de entendimento do movimento, ampliando os olhares para a ação e participação feminina, para as relações de gênero. 
Além da categoria de gênero, o conceito de representação também nos é caro para pensarmos as narrativas construidas acerca das mulheres no movimento do Contestado e como isso toma forma nas práticas históricas ao perpetuar estereótipos atribuídos ao feminino. 0 conceito representação carrega consigo várias abordagens, entretanto, não temos a intenção de esgotá-lo, e sim apenas apontar algumas construções do que "representação" pode significar conceitualmente e como hoje o termo é amplamente utilizado no campo historiográfico. Dentre as variadas possibilidades, pautamo-nos em Roger Chartier (1990, p. 17) que pensa representação como "identificar o modo como em diferentes lugares e momentos uma determinada realidade social é construida, pensada, dada a ler". O que mostra como é importante problematizar o conceito e ter "por objetivo a compreensão das representações do mundo social, que o descrevem como pensam que ele é ou como gostariam que fosse" (CHARTIER, 1990, p. 19).

A construção do próprio termo representação no desenrolar histórico acaba recebendo influências e novas interações, o que reforça a dinamicidade da sociedade em sua relação com o tempo e as problematizações de cada época. Na presente abordagem e considerando as problematizações do objeto, bem como a subjetividade de quem escreve e suas intenções, a caracterização dada por Roger Chartier (2002, p. 100) parece-nos mais apropriada, a qual consegue melhor exprimir os objetivos propostos que relacionam o estudo das obras literárias:

\begin{abstract}
Uma história da literatura é, pois, uma história das diferentes modalidades da apropriação dos textos. Ela deve considerar que o "mundo do texto", usando os termos de Ricoeur, é um mundo de objetos e de perfomances cujos dispositivos e regras permitem e restringem a produção do sentido. Deve considerar paralelamente que "o mundo do leitor" é sempre aquele da "comunidade de interpretação" (segundo a expressão de Stanley Fish) à qual ele pertence e que é definida por um mesmo conjunto de competências, de normas, de usos e de interesses. 0 porquê da necessidade de uma dupla atenção: à materialidade dos textos, à corporalidade dos leitores.
\end{abstract}

Seguindo os dizeres de Roger Chartier (2002), os modos como um texto, um pensamento ou uma imagem são dados a ler acabam se transformando entre os momentos de sua produção e as outras realidades distintas das que foram produzidas. Todavia, muito mais que pontuar paralelismos entre "ficção" e "realidade", procuramos problematizar os romances e suas construções acerca do movimento do Contestado e o papel que foi atribuído às mulheres partícipes, sob os olhares de ambos os autores das obras analisadas.

A obra Império caboclo é para Donaldo Schüler $(2010$, p. 1) não apenas uma espécie de retrato do evento, mas também uma revivência dele como espectador: 
E eu nasci nesse contexto. Conheci caboclos que apareciam na bodega de meu pai. Eles não tinham noção do valor do dinheiro porque viviam em outro sistema. A cultura do imigrante era a da construção, a do enriquecer. 0 caboclo, não. Eles ganhavam o salário do trabalho semanal e iam para a bodega do meu pai, onde passavam o sábado e o domingo tomando cachaça. Eu vi coisas impressionantes: briga com facão, morte, disputas. Aquilo era uma espécie de faroeste. Havia muita violência. Esse mundo é o meu subsolo. No fundo éramos estrangeiros ocupando o território de outros. Bem, isso está diretamente ligado ao messianismo, pois nessa época aquelas pessoas tinham saudade da monarquia, que as protegera. Aquilo foi uma enorme tristeza: brasileiros contra brasileiros. Minha infância está sedimentada ai: entre a crueza, a aspereza e a fantasia que tudo aquilo nos provocava. Império caboclo é, assim, um retorno a episódios vivenciados na infância.

E acrescenta o que liga a narração do fato e a criação ficcional tangente:

A minha história está diretamente ligada ao Contestado. Em 1910 foi construída a estrada de ferro que vinha de São Paulo e cortava o centro de Santa Catarina. Uma das cláusulas para a construção era a cessão de trinta quilômetros de terra de cada lado da linha do trem. Além das terras contratadas, muitos pinhais foram comprados pela companhia construtora. Tudo isso para industrializar e exportar madeira. Nesse momento, começa um grande desmatamento daquela região, que se caracterizava pela produção do pinhão. 0 pinhão era muito importante para a população que lá vivia, pois com a produção do pinhão eles se alimentavam, engordavam os porcos. 0 desmatamento desabrigou parte dessas pessoas, então começa o movimento dito messiânico. João Maria e, depois, José Maria surgem nesse contexto de devastação. As pessoas foram desabrigadas. Os descontentes se reuniram com a finalidade de agredir os agressores. Talvez tenha surgido lá o primeiro movimento dos sem-terra no Brasil. Uma das preocupações do governo republicano foi povoar aquela região com estrangeiros ou descendentes de estrangeiros. Houve campanha de colonização. Aqui no Rio Grande do Sul, por exemplo, eles mandavam agricultores para aquela região. As cidades que se formaram na região contestada são, em sua grande maioria, constituídas de descendentes de alemães e de italianos. Meu pai foi para lá por volta de 1930 e abriu uma bodega, uma espécie de supermercado, onde se vendia de tudo: banha, cachaça, suprimentos (SCHÜLER, 2010, p. 1).

Nessa narração, o autor trabalha com uma voz masculina que conta a história e participa dele, além de tentar destilar as inúmeras influências que cercam o movimento Contestado, não diretamente o ligando a revelar o papel das mulheres, mas de inúmeros agentes sociais que passam por vezes invisibilizados. Como salienta Hayduke (2009, p. 16): "0 romance mostra-se assim uma excelente fonte para estudar a experiência moderna em 
suas diversas vertentes, de retratar uma experiência singular em um contexto espaço-temporalmente dado".

Em 0 bruxo do Contestado, de Godofredo de Oliveira Neto, publicado em 1996, há, em sua elaboração, a presença de grandes debates sociais, além de aspectos relacionados à Guerra do Contestado, à Segunda Guerra Mundial e aos problemas enfrentados pelo Brasil na ditadura militar. A obra tenta também inserir a discussão da participação das mulheres no movimento:

Uma das minhas grandes preocupações quando da composição do 0 Bruxo do Contestado foi a visão das mulheres sobre os fatos - trabalho com Machado e a visão da Capitu sempre escamoteada é a que chama a atenção. Primeiro, a narradora (Tecla) é uma mulher, mulher que conheceu três conflitos: o Contestado através do relato dos empregados domésticos da casa de seus pais, a segunda guerra mundial e os seus efeitos no Brasil e o golpe de Estado de 64. A História do Brasil contada por uma mulher?

Sua narrativa gravita em torno dos olhares das mulheres sobre o enredo tratado, no qual elas narram e intermedeiam a narrativa e participação dentro da obra.

Todas são agentes históricas dentro da trama da obra e na leitura dos fatos históricos. Quis fazer exatamente isso (visibilizar as mulheres), mas poucos leram nessa direção, por isso fico muito sensibilizado com essa proposta de leitura. Só Gerd conceitua à sua maneira a história monumental. Segundo a pesquisadora Mayara Ribeiro Guimarães, "a leitura que esse camponês faz do passado se assemelha à conceituação de história monumental, isto é, eleva um determinado episódio a um nível de grandiosidade extrema". Como a História sempre fez. No Bruxo as mulheres protagonizam, interpretam, mediam e buscam a verdade. Mas o autor da obra luta, consigo mesmo e com o seu narrador, às vezes não sai o que eu pretendia. E, ademais, como digo, os leitores lerão ao jeito deles e pronto ${ }^{8}$.

Nota-se que o presente das obras literárias absorve os debates historiográficos mais recentes, cada autor se utiliza de parâmetros investigativos à sua maneira, assim como contribui com construções e representações, as quais são ressignificadas pelos leitores e pelas leitoras.

Podemos assim entender não o movimento em si, em seu tempo, mas as representações dadas aos fatos e suas construções no presente em que as obras foram escritas, e quais traços podem ter sido anexados à narrativa, diante dos inúmeros debates que ocorreram

7 - Oliveira Neto em entrevista concedida a Fábio da Silva Smoliak (por e-mail) em 27 de agosto de 2017.

8 - Oliveira Neto em entrevista concedida a Fábio da Silva Smoliak (por e-mail) em 27 de agosto de 2017. 
entre o fato e a narração, mas ao mesmo tempo que pode ou não adquirir teor das discussões que perpassam e criam nuances em suas palavras.

Nesse sentido, tanto a história quanto a literatura podem ser entendidas como representações, ainda que os compromissos de suas narrativas sejam um ponto importante de sua diferenciação, como salientou Sandra Jatahy Pesavento (2003). Além disso, a operação de aproximá-las ou distingui-las já não se sustenta em jogos dicotômicos tais como verdade/ falsidade, real/ficção, acontecimento/ imaginação (MARTINS, 2016, p.84).

Muito além de comparar ficção e real, considerando que o real pode ser ficcional também, este artigo busca entender a representação do papel que as mulheres ocuparam e como essa participação é retratada nas obras em questão que utilizam o movimento do Contestado como cenário, assim como perceber se houve avanços com os debates surgidos e ampliados pelos estudos historiográficos sobre as mulheres ou se simplesmente estão novamente construindo representações aos olhares de leitores e leitoras.

\section{A PARTICIPAÇÃO DAS MULHERES NO MOVIMENTO DO CONTESTADO: SOB O OLHAR DAS OBRAS ANALISADAS}

0 processo de colonização europeia e cristã propagou por toda a América padrões idealizados da imagem das mulheres, baseados na figura da Virgem Maria, em que os arquétipos são delineados segundo a acepção religiosa invasora e requerendo novos padrões de comportamento e pensamento das pessoas que aqui habitavam ou chegavam. A representação da Mãe Virgem, pacífica, submissa aos desígnios de uma divindade, modelo de maternidade e de esposa, foi, de forma paulatina, sendo introjetada socialmente, de modo violento ou não, na vida de mulheres e homens, e passou ao longo dos tempos por ressignificações e trocas culturais. E de um extremo ao outro do continente essas representações e ressignificações encontraram lugar, em maior ou menor grau, penetrando na sociedade que não era cristã e que tinha um formato muito próprio de seu relacionamento com o sagrado ou o religioso. Nesse sentido, o desígnio da religião cristã sobrepõe-se a vínculos - ou os cria que possam coexistir com a cultura indígena centrada e articulada sobre pisos sociais extremamente diferentes dos recém-chegados.

A propagação da figura mariana ocorreu em niveis diferentes no continente, mas que é marcante na nova sociedade que se ergue, e ainda hoje vemos sua força em nossos dias com a devoção que se tem à Virgem Maria. Essa valorização das virtudes de Maria, tida como modelo de mulher, em detrimento de outras formas de ser mulher, contribuiu para a difusão, em proporções variadas, do marianismo. 
0 marianismo encarado como um estereótipo derivado do culto católico à Virgem Maria aparece no Brasil como "a outra face do machismo", o marianismo é um edifício secular de crenças e de práticas relativas à posição das mulheres na sociedade. Conforme sua definição, "o marianismo é o culto da superioridade espiritual feminina, segundo a qual as muIheres seriam semidivinas, moralmente superiores e espiritualmente inferiores que os homens" (ARY, 1988, p. 114).

A construção cristã católica das representações das mulheres associadas à figura de Maria coloca-as numa posição às vezes de semidivinas, que guardam a moralidade social, porém ainda estão em condição de inferioridade aos homens. Isso fica evidente na consolidação hierárquica da Igreja cristã, na qual as mulheres podem se tornar instrumento do poder divino, desde que esse instrumento esteja submetido a um deus ou a um "falo" superior.

Essa representação mariana pode ser utilizada para problematizar a descrição das "virgens" nas fontes literárias analisadas, pois, embora aparentem ser retratadas como submissas, as obras demonstram como as narrativas vão suplantando as diferenças de gênero, no momento em que a característica de proximidade ao divino se sedimenta na sociedade que presencia o movimento do Contestado.

Ao longo dos cinco anos do conflito, o movimento do Contestado teve vários líderes. 0 primeiro foi o monge José Maria de Santo Agostinho, morto no primeiro combate com tropas do Paraná, inclusive duas jovens mulheres lideraram o movimento, Teodora e Maria Rosa, denominadas "virgens". Elas diziam ter visões com o monge nas quais recebiam as orientações do falecido. Assim exerciam o papel de líderes, mas ainda obedecendo a um "falo" espiritualmente superior, como salientam Carla Pinsky e Joana Maria Pedro (2012).

Maria Rosa do contestado. Essa menina de 15 anos, considerada santa pela população envolvida na Guerra de São Sebastião, afirmava ter contatos espirituais com o monge José Maria. Ela era conhecida por usar um longo vestido branco enfeitado com penas de tucano e adornado com fitas azuis e verdes. Para sua viagem ao espírito dos monges, trancava-se num quarto escuro, ouvia as instruções daqueles líderes espirituais e as transmitia a um conselho de guerra que já dispunha de dezenas de informações sobre a movimentação das tropas adversárias, particularidades do terreno, poderio de fogo inimigo, local de concentração etc. Maria Rosa voltava à câmara escura, passava as ponderações do conselho militar aos monges e retornava sempre com a decisão final (OLIVEIRA NETO, 1996, p. 93).

A partir desse fragmento da obra literária 0 bruxo do Contestado, percebemos que a tenra idade da liderança humana pouco preocupava, já que a ideia de uma "virgem" e toda a carga ideológica formada na sua construção divinizavam suas palavras, e que ainda assim era outorgada pelo masculino superior, que, mesmo em outra vida, creditava uma fala de poder 
espiritual e patriarcal acima da mulher que liderava os seguidores do monge. A pureza construída até nas suas vestimentas brancas e a inviolabilidade de seu corpo davam respaldo a suas decisões e acabavam criando a representação da virgem com alguma espécie de poder, todavia subordinada às revelações de um poder superior, como se nota nas fontes analisadas.

De Winchester, Mauser e espada em punho, devemos atacar de surpresa, tal dia, tal hora e em tal lugar o pelotão de peludos que nos ameaça. A ordem vinha com chancela e endosso sagrados! Dava sempre certo, a vitória era sempre garantida. Num alojamento militar de Curitiba, um fotógrafo registrou, nos anos de 1940, a seguinte inscrição na parede ao lado dos beliches: "Maria Rosa do contestado para chefe do serviço secreto e comandante das operações militares!" (OLIVEIRA NETO, 1996, p. 93).

Mais que a destemida atitude da jovem no fragmento literário, podemos problematizar o reconhecimento de suas táticas bélicas, que eram repassadas e aceitas como iluminação divina. Se as orientações dela eram a visão do monge revelada espiritualmente ou apenas suas vontades de mulher colocando em prática seus planos de guerra, isso não nos compete averiguar, o que nos importa é a forma como sua presença, sua participação e suas decisões - ainda que a chancela masculina de um ente espiritual superior desse poder às suas palavras - aparecem nas narrativas literárias e nos remetem ao modelo de pureza da Virgem Maria, da pacífica, da iluminada, que recebe uma revelação "divina". Usando do poder patriarcal religioso, ela conseguiu liderar em batalha, passando assim de uma mera agente passiva a uma agente ativa dentro do conflito, o que demonstra como o modelo mariano - o marianismo - estava impregnado de sentido nessas narrativas.

No que tange às manifestações orais, nota-se que as formas de expressão ágrafas, que não depositam sua sugestão/indicação semântica em signos linguísticos, correspondem à origem de todas as narrativas, sejam para contestá-las ou para dar vida e continuidade a elas (SÁBER, 2010).

Essa sertaneja, tida desde logo como profetiza e santa, pelas suas ligações com o mundo misterioso dos fenômenos sobrenaturais, adquiriu domínio absoluto sobre os crentes. Ela designa os chefes, comandantes de briga e de reza, da forma de piquetes destinados a arrebanhar gado, convencer vizinhos recalcitrantes, efetuar prisões, expedir bombeiros junto aos peludos ou pés redondos. Os cabalares e espiões eram sumariamente fuzilados (WOLFF, 2012, p. 1535).

0 povo materializou nas cantigas a herança da tradição oral, a expressão popular do que sentia, presenciava ou ouvia falar, em um país onde muitos não sabiam ler ou escrever. Na época, a oralidade foi a válvula de escape para que as futuras gerações pudessem assimilar 
os fatos pela ótica dos(as) caboclos(as) que dela participaram e acabam captando muito da realidade não historicizada:

\author{
Lá a "Virgem" Maria Rosa \\ No reduto é que mandava, \\ Ninguém mais intrometia \\ Pois só ela comandava; \\ Nomeou todos cabeças \\ Os que mais considerava (WOLFF, 2012, p. 1536).
}

A descrição ficcional e a representação na literatura podem assim ser debatidas nos estudos sobre o movimento, uma vez que a participação das mulheres como agentes históricos - seja Maria Rosa, Teodora ou várias outras - não passa despercebida, pois quem comandava o reduto e constituia suas leis eram essas mulheres, as "virgens". Essa caricatura ou representação dada às mulheres pode ser vista também na obra Império caboclo:

\footnotetext{
Constantina costumava caminhar pelo pinhal e receber a chuva de luz coada pela alta gaIharia dos pinheiros. Era uma luz verde, cheirosa, compacta, luz que Ihe descia pelo corpo como as águas da cascata e Ihe incendiava o rosto. Era uma luz masculina, penetrante que Ihe picava a pele como as folhas pontudas dos pinheiros. Um dia, olhou fixamente para o al to e viu um rosto severo de um homem, um rosto que no silêncio era uma ordem, o rosto de seu padrinho, José Maria. Quando saiu da floresta, todos Ihe viram as faces iluminadas, cânticos de júbilo dançavam nos seus lábios rubros, e ela convocou homens, mulheres e crianças para ver o semblante iluminado de José Maria. Todos seguiram o dedo apontando e terminaram num vazio, o céu vazio, silêncio desde a morte de José Maria. Constantina, a iluminada, ouviu vozes no céu que ninguém ouvia e irrompeu em cânticos que ninguém cantou e seu rosto desabrochou como um botão de rosa, por isso todos a chamaram a iluminada (SCHÜLER, 2005, p. 55).
}

Fica evidente que a figura de Constantina era a de uma mulher que comandava os rumos da resistência, entretanto, assim como Maria Rosa, ela estava subordinada à figura mítica de um homem, no caso o monge. As mulheres na qualidade de herdeiras de Maria divinizada, tomada como modelo de submissão, pureza e sofrimento, são aparentemente revalorizadas e tidas simbolicamente como salvadoras da sociedade no seu papel maternal idealizado (ARY, 1988). É o que podemos notar neste fragmento da obra:

Os homens, as mulheres e as crianças viram em suas ordens e gestos a força de São Sebastião para livrá-los do poder dos inimigos. Constantina reconheceu que a voz de 
José Maria agora falava nele. A liderança era legitimamente dele. Constantina recebeu a primeira chibatada no quadro cercada de povo com alívio. As lágrimas que the banhavam o rosto a lavavam de todas as culpas, o sangue que Ihe brotava nas costas morenas era ungüento para sua alma ferida. Sob os flagelos, Constantina sentia-se a criança que sempre fora e sempre desejava ser. 0 sangue e as lágrimas, purificando-a, a fazia criança. 0 bater ritmado a punha em contato com o poder. Ela uivava de dor e prazer. Se a dor não terminasse nunca mais, ela poderia sentir-se para sempre poderosa. A sua era também a dor da mãe e de todos os que sofrem. Voltava a sentir-se virgem e poderosa. Ergueram-na desfalecida, revestido o rosto com a serena paz dos justos (SCHÜLER, 2005, p. 67).

Constata-se ainda o poder dado à sua líder na trama literária, que é marcada dicotomicamente pelo poder que fora usurpado por um homem. Mesmo sendo agredida, ela via nesse contexto uma maneira de voltar a ser "iluminada". Sua dor era humana, de uma mãe parindo. Depois de todo o sofrimento perpetrado, ainda desfalecida, ela apresenta um rosto sereno e em paz, o que revaloriza um caráter de submissão, pureza e sofrimento - a mater dolorosa - que se enquadra no bojo da estrutura do marianismo, a redentora.

Em contrapartida à tentativa de retirar dessas mulheres a condição humana e elevá-las ao mítico, demonstrada nas obras literárias, é importante considerar não somente a tarefa do marianismo, como também outras construções sociais que permearam o imaginário social, como o mito das amazonas.

A imagem de mulheres pegando em armas, tida como monopólio masculino, também as transporta ao mundo das imagens extra-humanas, como ocorre com o mito das amazonas, que, debatido nos limiares do Brasil, cria a caricatura de que as mulheres transcendem a outro patamar ao se tornarem guerreiras, e nisso também se podem encontrar traços que se assemelham às representações das mulheres do Contestado.

Entre o mítico e o real, notam-se traços de construção que se remetem ao mito das amazonas, que mescla exotismo e fantasia no que tange ao Brasil. De acordo com Johnni Langer (2001, p. 60), "Sobrevivendo ao iluminismo, ao contrário de outras fantasias coloniais, as mulheres guerreiras foram identificadas nos séculos XVIII e XIX como sendo uma tribo indígena, herdeiras de antigas civilizações desconhecidas de nosso país". Esse mito conseguiu se manter vivo não apenas na literatura e na historiografia, mas também no imaginário social sobre o povo e o território nacional.

Atrelado à construção de um passado mais heroico, o mito das amazonas pode ter sido ressignificado para explicar as mulheres que pegaram em armas, lutaram e não dependeram exclusivamente de um homem como protetor, tornando-se protagonistas de suas histórias. Nesse enredo, percebe-se, numa das fontes em estudo - em 0 bruxo do Contestado -, uma similaridade entre a mítica das amazonas com sua sensualidade e as jovens chamadas de 
"virgens" que, de uma forma ou de outra, participaram no movimento do Contestado, reavivando o caráter de guerreira, como evidenciado no seguinte fragmento:

\begin{abstract}
Alguns mestiços de bugre com negro lá do Contestado que agora vivem aqui na reserva dos indios relatam muitas histórias daquela guerra. Uma mestiça conta que existiam grupos de mulheres que exerciam o papel de chamas - como pra pegar passarinhos - de soldados inimigos. José Maria escolhia 12 entre as mais bonitas, com um detalhe: tinham que ter os cabelos ou bem pretos ou bem louros. Formavam fila, duas a duas, uma de cabelos pretos e uma de louros, as duas de trás invertidas, cabelos louros atrás dos morenos, como um ziguezague. Vestiam camisões de homens semiabertos, deixando entrever a nudez. As seis duplas entravam mata adentro cantarolando. Um cabra jura ter visto essas mulheres atravessando a pé o Rio Iguaçu, perto de Porto União, sem tocar na água. Voavam! Os soldados, quando viam aquelas deusas, endoideciam (OLIVEIRA NETO, 1996, p. 44-45).
\end{abstract}

Entende-se no fragmento a tentativa de representar mulheres guerreiras, entretanto, notam-se traços de um patriarcado messiânico, já que não eram todas as que queriam ou iriam participar, mas só as "mais bonitas" seriam escolhidas pelo chefe José Maria. Elas utilizavam a sensualidade e as vestimentas como armas para desarmar os soldados, entravam mata adentro, andavam sobre as águas, voavam, isso tudo mexia com o imaginário dos soldados que, ao verem "aquelas deusas, endoideciam".

A sensualidade feminina retratada na obra literária parece retirar o papel de guerreiras, de combatentes e o caráter carnal das mulheres, para sobressair uma imagem idealizada de beleza, sedução, vistas como deusas que até voavam. Mulheres "chamas", ou seja, chamariz para atrair os soldados inimigos.

Se, por um lado, eleva-se o poder sedutor e carnal das mulheres subordinadas ao comando messiânico, as guerreiras, por outro, que usam esse fetichismo atraíam os soldados e derramavam seu sangue. Assim, parece haver uma dualidade de papéis femininos no movimento, o de "virgens" inspiradas por revelações e o de mulheres ativas, as guerreiras, ainda que escolhidas pelo monge para o combate.

Ênio, com o semblante sério e circunspecto, seguiu narrando nos mínimos detalhes a história lembrada pelos cafuzos. A mistura dos cabelos claros e escuros naquela desordem ordenada embaralhava os olhos e o sexo da tropa. Os soldados largavam os fuzis e, abrutalhados, se lançavam ao prazer. Prazer de pouca duração. Todas as jagunças traziam punhais escondidos. Os praças, ávidos de penetração, se tornavam, de súbito, amantes passivos da lâmina pontiaguda que, esta sim, os penetrava, depois, ainda agonizantes no chão, recebiam das virgens um tiro de fuzil - arma que tinha sido deles - nos testículos (OLIVEIRA NETO, 1996, p. 45-46). 
De um caráter imaculado passam a fazer o que no imaginário seria másculo. Por meio da brutalidade, matam e, antes que o sangue do inimigo pare de correr nas veias, terminam o serviço com um tiro nos testículos dos soldados. Atacam o âmago do sentimento de superioridade masculina, já que toda a linguagem corrente está impregnada por um dimorfismo cultural, "falocêntrico", que transforma o universo numa dualidade sexuada e hierarquizada, cujo polo superior é representado pelo homem-marido-pai (adulto másculo), enquanto o polo inferior é representado pela mulher-esposa-mãe. Deixam o estereótipo da "mulher recatada e do lar" para a sanguinária amazona (ALVES, 2004).

Na obra Império caboclo, erguem-se representações que misturam fé e força das mulheres no movimento. Maria Rosa atua, a um só tempo, como virgem, mãe, mulher e carrasco. Sempre aparecia em seu cavalo branco empunhando uma espada e uma vara de marmelo. Batia violentamente nos homens, que se rendiam às suas vontades. Também sentia piedade das crianças e de inocentes doentes, e nela pairava a figura da Virgem Maria, acalmando seus filhos. Com tanta responsabilidade, não via os jagunços como homens e não deixava que a vissem como mulher (SILVEIRA, 2008).

Outra representação presente na obra Império caboclo é a construção do papel das "baianas", no qual se misturam a sedução e a morte pelas mãos macias de uma mulher.

Quando o soldado me agarrou, eu fiz cosquinha nele, e ele rolou no chão, de gozo, feito cachorrinho de perninhas para o ar. Eu continuei parada com um pé à direita, outro à esquerda do meu valente agressor. Fui arregaçando devagarinho minha saia de baiana para que ele pudesse contemplar todinha a paisagem relvada que o fazia nas circunstâncias o homem mais feliz do mundo. Ele me puxou pelo braço, eu despenquei por cima dele. Dei mordidinhas na orelha esquerda e na direita, ajeita-Ihe o cabelo em desalinho. Ele sorriu que nem criança. Senti as mãos dele subindo pelas minhas pernas. Abri a blusa e Ihe ofereci o seio. Ele sugou deliciado. Afaguei a pele debaixo do braço esquerdo para não errar o golpe. Empurrei o feno entre as costelas como se faz com porco destinado ao sacrificio, a faca deslizou mansinha sem eu ouvir ele gemer. Partiu dessa para melhor com os beiços grudados no meu peito. Ainda murmurei uma cantiga de ninar (SCHÜLER, 2005, p. 114-115).

Em meio a um ato violento, a narrativa demonstra como o "valente agressor" é tratado por aquela figura feminina, que, utilizando-se da sensualidade, desarma seu algoz, a ponto de deixá-lo docilmente desprotegido. Ela Ihe oferece o afago de mãe, os carinhos de mulher e o sorriso de criança, e, nesse ritual de violência - e prazer -, tira a vida do soldado à medida que a lâmina da faca penetra suas costelas, "como se faz com porco destinado ao sacrifício". Nesse ato, não vemos uma mulher divinizada, mas uma mulher que se utiliza de sua força aliada à sensualidade para, durante o conflito, revelar-se não apenas como "virgem" ou 
pacifica e submissa, mas também como guerreira e combatente. Mulheres ativas, "baianas", e engana-se quem pensa que foram mulheres isoladas que o fizeram.

Quando conseguimos atravessar a floresta, estávamos num campo aberto. Passamos por uma rocinha de milho, sabe o que havia nela? Baianas. Foi como estou Ihe falando, baianas. Baianas foram as primeiras criaturas vivas que encontramos. Elas se levantavam no milharal, acenavam e sumiam. Em dezenas, todas bonitonas e jovens. Gritos de advertência não contiveram o ímpeto de muitos dos nossos. Um amigo meu me cochichou ao ouvido: se é para morrer, prefiro morrer nos braços de uma baiana e se mandou. Nunca mais voltou. Como não voltaram centenas de outros mais fracos que a sedução (SCHÜLER, 2005, p. 114-115).

Constata-se, assim, que esse movimento de mulheres guerreiras não formou eventos isolados e unitários, mas eram empregados grandes contingentes que demonstravam imensa destreza diante do perigoso plano do qual elas faziam parte. Demonstraram a mesma belicosidade que um homem na frente de batalha, sangue frio e ardente sensualidade, são as dicotomias encontradas na representação das baianas. Cabe problematizarmos se isso continuaria, já que "o mesmo movimento ideológico que direciona as mulheres para fora do monopólio da domesticidade em favor do 'esforço de guerra' redireciona o fluxo para cuidar dos 'heróis cansados'[...] e lhes deixar os postos de trabalho", mas, além, elas ocuparam um papel eminentemente viril e masculino (MOTTA, 2012, p. 299).

\footnotetext{
Traduzido como espaço eminentemente masculino, o militarismo e a virilidade encontram-se entrelaçados como a capacidade para a guerra, para a ação, para a violência. [...] De qualquer maneira, a abstração "mulheres" é distanciada da capacidade de esforço físico e agressividade e também da capacidade guerreira. Mas, no decorrer do século XX, tanto a concepção de corpo moldável pelo treinamento quanto a experiência da guerra total modificam esse horizonte (MOREIRA, 2010, p. 324).
}

Para além de uma manutenção do processo que equipara os guerreiros, devemos enxergar que, nesse contexto, as mulheres ocuparam o reduto mais masculino, o monopólio sobre a violência, que é tida como sinônimo de virilidade. Entretanto, isso não apaga a dicotomização: de um lado, as representações mostram que as mulheres passaram de reveladoras de táticas de guerra e de inspiradoras a atuantes combativas na guerra, e, de outro, evidenciam sua separação, já que não lutavam ao lado de homens do grupo, e sim contra os soldados inimigos. Com base nisso, podemos pressupor que poderiam ser tidas como um grupo próprio que lutava em batalhas especificas, lideradas por elas mesmas, sozinhas no front enfrentando os inimigos, ou então foram assumindo a linha de frente a partir das mortes dos homens dos povoados, cabendo a elas fazer a defesa, combater, guerrear. 


\section{ALGUMAS CONSIDERAÇÕES FINAIS}

As narrativas literárias e historiográficas abordam um contexto "conhecido", o movimento do Contestado, que confere protagonismo às mulheres, sujeitas da história, evidenciando sua participação e contextualizando literariamente o atual debate acerca da história das mulheres e dos estudos de gênero num intervalo de quase um século entre a data em que ocorreu o movimento do Contestado. Cabe ressaltar que as fontes literárias analisadas não tratam somente das mulheres que formam o foco do trabalho, mas permitem abordar outros aspectos que norteiam suas vidas como a violência vivida dentro de casa, no espaço privado; a dominação masculina e o poder patriarcal que se sobrepõem a elas, estipulando papéis sociais e aceitáveis segundo o olhar social vigente.

As fontes evidenciam que as mulheres participaram de modo notório no movimento do Contestado e foram retratadas como o caso das "virgens", das "chamas", das "baianas" que com suas revelações, armas em punho, derramando sangue, seduzindo, ferindo, matando, combateram não somente contra os inimigos, mas também contra a dominação masculina, patriarcal, seja nos confrontos com as táticas de guerra ou então se apropriando do imaginário social e das representações acerca do feminino para usufruir de espaço, de poder, de tomada de decisão na efetividade de suas campanhas.

As mortes retratadas nas fontes mostram não apenas a morte em si, mas também apontam a simbologia que está presente, pois o ataque não é somente físico, é também psicológico, atacando muitas das barreiras impostas pela sociedade como balizadora para a vivência feminina.

0 uso comparativo ao mito das amazonas, realizado neste trabalho, é uma possibilidade para evidenciar que as mulheres envolvidas no movimento foram "desumanizadas", alçadas como algo místico, como algo que foi retirado delas, a concretude, a condição de mulheres de carne e osso, reais, mortais, e as transportou para uma "divinização".

Assim, o mito serve para amparar uma idealização do feminino da época, na qual as mulheres eram apresentadas como frágeis, e as fontes questionam essas ideias de meras acompanhantes de suas famílias e mostram o protagonismo no conflito. A comparação entre as obras literárias analisadas e a relação entre a história e a literatura revelam debates de época, similaridades e representações variadas, e apontam ainda a maneira como as mulheres do Contestado são retratadas, ora como "virgens", pacíficas, passivas, ora como guerreiras, ativas, protagonistas no processo histórico.

A constatação de aspectos do marianismo nas obras analisadas contribuiu para a percepção do aspecto religioso, do sagrado, do simbólico, permitindo problematizar a construção das representações do feminino, ora materializada na visão da santa, divinizada, "iluminada", modelo de mãe que traz "ternura, aconchego e calor", de mulher "recatada e do lar", estereótipos tão presentes nos territórios nacional e latino-americano, já que a religião de Espanha 
e Portugal que aqui desembarcaram era o catolicismo e que levou o Brasil a ter como padroeira nacional Nossa Senhora de Aparecida, exemplo vívido dos anseios e das crenças que permeiam a construção da nação.

É evidente que a análise das obras e as problematizações realizadas não são únicas, fixas, nem leis imutáveis, cada pessoa lerá as fontes e criará correlações e comparações próprias de suas interpretações e sentidos. 0 importante é que a análise realizada colabore para entender o processo de construção das obras, as narrativas acerca da participação das mulheres no movimento do Contestado e a relação entre história e literatura que podem ter influenciado a forma como foram escritas na atualidade.

Temáticas como o alcoolismo, a violência familiar, a violência infantil e a própria construção do papel das mulheres no Contestado podem ser objetos de estudo e problemáticas de pesquisas futuras, e ainda temas de interesse de leitoras e leitores, considerando que o entendimento sobre as obras será sempre definido por cada pessoa que faça a leitura.

Os temas debatidos perpassam a sociedade, a literatura e todos os demais agentes, absorvendo contextos atuais e visualizando diferentemente o passado, e, nesse processo de escrita da história e de relação com a literatura, apresentam-se sujeitos(as) esquecidos(as) que são de extrema importância para compreender um pouco mais das narrativas e construções sobre os acontecimentos e as experiências de mulheres e homens. 0 importante é abrir 0 leque de possibilidades, atentando-se para as relações sociais que nos cercam, os imbricamentos entre mulheres e homens, questionando as velhas relações de poder, o patriarcalismo, problematizando discursos essencialistas e naturalizados, entendendo-os como parte da construção sociocultural e das narrativas reproduzidas na sociedade, e que, portanto, são passiveis de transformação.

\title{
Between literary and historiographic narratives, women in the movement of the Contestado: "virgins" or protagonists?
}

\begin{abstract}
This article aims to analyze, in an interdisciplinary perspective, the construction of literary narratives about the female participation in the Contestado movement, which unfolded in Brazil at the beginning of the 20th century, relating them to historiographical narratives. For that, we present the historical context and the relation between literature and historiography, discussing how the representations of the women involved in the movement are constructed and how they are portrayed in the works used as sources: Império caboclo, written by Donaldo Schüler, of 2005, and 0 bruxo do Contestado, of 1996, written by Godofredo de Oliveira Neto. We have as reference the history of women and gender studies which make it possible to address social and cultural issues, the narrative construction of female representations and the dichotomous vision between "virgins" or protagonists in the movement, the sources of the research. Thus, the comparison between the literary works analyzed and the relationship between history and literature revealed period debates, similarities and varied re-
\end{abstract}


presentations, denoting the manner in which the women of the Contestado are portrayed, sometimes as "virgins", peaceful, passive, sometimes as warriors, active, protagonists in the historical process.

Keywords: Women. Contestado. Representation. Literature. Narrative.

\section{REFERÊNCIAS}

ALVES, L. Guerra do Contestado. [S. I.: s. n.], 2004. Disponivel em: https://pt.scribd.com/ doc/49330914/Guerra-do-Contestado. Acesso em: 28 dez. 2017.

ANTONELLI, D. A Nova Jerusalém do Contestado. Gazeta do Povo, 2013. Disponivel em: http://www.gazetadopovo.com.br/vida-e-cidadania/a-nova-jerusalem-do-contestado41ynh0j1ebu8y3290gfke4rpq. Acesso em: 20 nov. 2017.

ARY, Z. Marianismo como culto da superioridade espiritual da mulher. In: INTERNATIONAL CONGRESS OF AMERICANISTS, 46., 1988, Amsterdam. Anais [...]. Amsterdam: [s. n.], 1988.

BARBOSA, C. C. A representação literária da Guerra do Contestado: amálgamas ficcionais em O bruxo do Contestado. Terra Roxa e Outras Terras: Revista de Estudos Literários, v. 21, p. 6575, set. 2011.

CHARTIER, R. A história cultural: entre práticas e representações. Rio de Janeiro: Bertrand Brasil, 1990.

CHARTIER, R. À beira da falésia: a história entre certezas e inquietude. Porto Alegre: Editora UFRGS, 2002.

EXÉRCITO BRASILEIRO. Histórico. Disponível em: www.eb.mil.br|. Acesso em: 19 dez. 2017.

FRAGA, N. C. Mudanças e permanências na rede viária do Contestado: uma abordagem acerca da formação territorial do sul do Brasil. 2006. Tese (Doutorado em Meio Ambiente e Desenvolvimento) - Universidade Federal do Paraná, Curitiba, 2006.

GAFFO, B. C. A nova história cultural e a utilização da literatura para pesquisa historiográfica. Londrina: UEL, 2003.

HAIDUKE, P. R. A. A modernidade entre o desencanto e a idealização: um diálogo entre história e literatura a partir do romance $A$ la recherche du temps perdu, de Marcel Proust. 2009. Dissertação (Mestrado em História) - Universidade Federal do Paraná, Curitiba, 2009.

LANGER, J. Ruínas e mito: a arqueologia no Brasil império. 2001. Tese (Doutorado em História) - Universidade Federal do Paranã, Curitiba, 2001.

MARTINS, J. V. O reino encantado do sertão: uma crítica da produção e do fechamento da representação do sertão no romance de Ariano Suassuna. 2016. Dissertação (Mestrado em História) - Universidade Federal do Rio Grande do Norte, Natal, 2016. 
MOISÉS, T. J. Sexualidad en Mesoamérica: machismo y marianismo. Revista de Investigaciones de la Universidad Don Bosco, v. 1, n. 1, p. 45-53, 2012.

MOREIRA, R. Virilidade e o corpo militar. História: Debates e Tendências, v. 10, n. 2, p. 331335, jul./dez. 2010.

MOTTA, A. B. Mulheres velhas - elas começam a aparecer... In: PINSKY, C. B.; PEDRO, J. M. (org.). Nova história das mulheres no Brasil. São Paulo: Contexto, 2012. p. 84-104.

OLIVEIRA NETO, G. de. O bruxo do Contestado. Rio de Janeiro: Nova Fronteira, 1996.

PINSKY, C. B.; PEDRO, J. M. Mulheres: igualdade e especificidade. In: PINSKY, J.; PINSKY, C. B. (org.). História da cidadania. São Paulo: Contexto, 2012. p. 265-310.

SÁBER, R. L. Literatura: bússola para a descoberta da brasilidade. Reuni, Pouso Alegre, n. 4, p. 265-279, 2010.

SCHÜLER, D. Império caboclo. 2. ed. Florianópolis: Movimento, 2005.

SCHÜLER, D. Critica. Sibila, ano 18, jun. 2010. Disponivel em: https://sibila.com.br/critical donaldo-schueler/3783. Acesso em: 20 nov. 2017.

SCOT, J. Gênero: uma categoria útil de análise histórica. Educação e Realidade, Porto Alegre, v. 15, n. 2, p. 5-22, jul./dez. 1990.

SILVEIRA, C. R. Questões de gênero; Império Caboclo; Violência do corpo e da alma feminina. Florianópolis: UFSC, 2008.

SOIHET, R.; PEDRO, J. M. A emergência da pesquisa da história das mulheres e das relações de gênero. Revista Brasileira de História, v. 27, n. 54, p. 281-300, 2007.

THOMÉ, N. A insurreição xucra. In: ESTADO DE SANTA CATARINA. Contestado. Florianópolis: Imprensa Oficial do Estado de Santa Catarina, 2016.

TRENTO, A. E.; LUDKA, V. M.; FRAGA, N. C. Guerreiras imortais do Contestado, as que tudo viam e faziam durante a guerra do extermínio. Geographia Opportuno Tempore, v. 1, n. 2, p. 272-292, 2014.

WOLFF, C. S. Em armas: amazonas, soldadas, sertanejas, guerrilheiras. In: PINSKY, C. B.; PEDRO, J. M. (org.). Nova história das mulheres no Brasil. São Paulo: Contexto, 2012. p. 423-446. 